\title{
The Influence of textile floor coverings on the indoor air quality
}

\author{
Silvia de Lima Vasconcelos ${ }^{1, *}$, Marcel Sattler ${ }^{1}$, Birgit Müller ${ }^{1}$, Wolfgang Plehn $^{1}$ and Wolfgang Horn $^{1}$ \\ ${ }^{1}$ HTW-Berlin, Fachbereich 1, Wilheminenhofstr.75A, 12549, Berlin, Germany \\ ${ }^{2}$ UBA, Umweltbundesamt, Wörlitzer Platz 1, 06844 Dessau-Roßlau, Germany \\ ${ }^{3}$ BAM, Bundesanstalt für Materialforschung und -prüfung, Unter den Eichen 87, 12205 Berlin, Germany
}

\begin{abstract}
Textile floor coverings are often used in offices and residential buildings. Large areas like meeting rooms, cinemas, theaters and hotels are often equipped with such coverings. They contribute to the comfort of the users as they provide high pedaling comfort and sound absorption. The weakness of these building materials is due to the odor emission that is released from the floor covering, which affects the comfort of the users. A bad air quality and the resulting dissatisfaction can lead to lower employee productivity [1] [2]. The research project of the Hochschule für Technik und Wirtschaft Berlin (HTWBerlin) is promoted by the German Environment Agency (UBA). The project has the following title: Lowemission and low-odor building products for energy-efficient buildings - Development of requirements and concepts for the Blue Angel from a climate protection perspective; investigates the emission and odor behavior of textile floor coverings (Emissions- und geruchsarme Bauprodukte für energieeffiziente Gebäude - Entwicklung von Anforderungen und Konzepten für den Blauen Engel aus Klimaschutzsicht; untersucht das Emissions- und Geruchsverhalten textiler Bodenbeläge). The results of the study are shown in this paper.
\end{abstract}

\section{Introduction}

Air, like water, is essential for the human body. Adults need about 12,000 liters per day to breathe [3]. This air consists mainly of nitrogen, about one fifth of oxygen and very small amounts of noble gases, carbon dioxide and other gases. In addition, traces of impurities (gaseous or particles) are found in the air [4]. Some of those substances that enter the body can be harmful to the organism, depending on the type and amount.

Whilst breathing the body gets on the one hand the supplies he need and on the other hand he smells the air. For smelling, humans have up to 20 million olfactory cells available [5]. The olfactory region of the nose is responsible for the odor perception. Its main task is the transformation of chemical stimuli into a neuronal pattern that allows humans to distinguish between different chemical stimuli [6]. The information is routed to the brain through electrical impulses through various switching points. In the brain, the smell is recognized by an interaction of different brain regions, including the limbic system. The close attachment to the limbic system creates an emotional association with the perception of smell, the so-called hedonic component (see 2.1). A human can distinguish up to 10,000 smells even if he can't verbally describe them [7]. Figure 1 illustrates schematically the different physiological phases of sensory perception. The sensory response is a quantitative as well as a qualitative assessment of the perceived stimulus.
Fig. 1. Physiological phases of sensory perception (source based on [8])

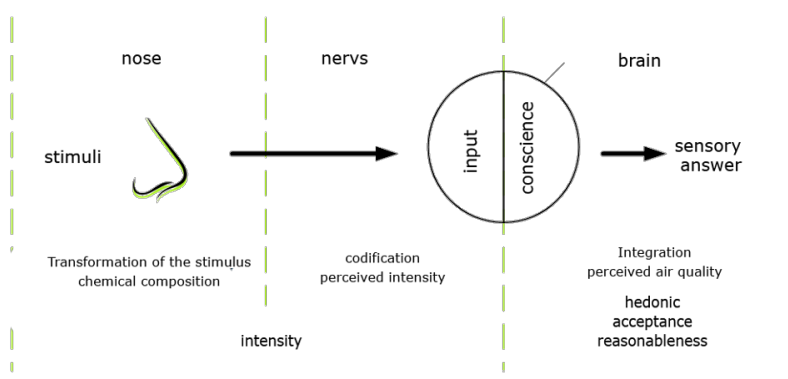

People living in temperate climates spend up to $90 \%$ indoors, breathing mainly indoor air [9]. Indoor air quality is therefore a health, but also an economic aspect, since productivity is strongly influenced and the ventilation behavior also changes the energy consumption of the building [10] [11]. Several studies with similar testing methods have shown that increasing air quality improves the efficiency of the office work, and this positive correlation brings economic benefits. An example is the study by Lagercrantz, et al. [2], which showed that both the perceived air quality and the productivity of 30 users tested decreased. These results are consistent with a study by Wargocki et al. [1], in which the same correlation has occurred. 
The most common indoor pollutants are gaseous pollutants, dust, allergens (such as pollen), microorganisms such as bacteria, viruses and fungal spores, and other particles [7]. They come mostly from internal sources such as building materials, furniture, decoration objects, cleaning agents, air conditioning systems [12] [13] and persons in the room, but they are also carried in by the outside air.

In addition, pollutants arise not only from emissions from these so-called primary sources, but also from interactions of the emitted substances on the surfaces with cleaning agents and other impurities [7]. Reactions of emitting compounds with reactive gases can produce secondary emissions [14] [15]. In addition to these emissions, sorption effects may also occur [16]. The perception of an odor does not allow any conclusions as to its relevance to health [17]. For some substances, the human nose is very sensitive. It becomes problematic if the concentration of an odorant is so low that it can't be measured, but nevertheless perceived with the nose. The detection and evaluation of odors therefore often eludes the known chemical-physical measurement method. Conversely, not every potentially dangerous substance can be detected in advance by its smell [18].

Air contains among other noble gases, carbon dioxide (CO2) and evaporated volatile organic compounds (VOCs), indoors in different proportions than outdoors. For the chemical-analytical assessment of indoor air quality in terms of health, the latter two are the most important ones: $\mathrm{CO} 2$, due to its importance as a guide to bio-effluents and VOCs due to their impact on health and well-being [19]. Both are analytically measurable and assessable.

In the indoor air around occur much higher VOCs concentrations than in the outside air. VOCs in the indoor air are from two major sources: bio-effluents (exhalations) from human respiration, perspiration and digestion, as well as emissions of building materials and furniture. These VOC-air mixture can cause eye irritation, headache, fatigue and dizziness, which are summarized under the term SBS (Sick Building Syndrome). A better air change rate can be helpful e.g. with an adequate, need-based ventilation [19].

In cooperation with the Bundesanstalt für Materialforschung und -prüfung (BAM); the HTWBerlin started in 2013 the research project "Lowemission and low-odor building products for energyefficient buildings - Development of requirements and concepts for the Blue Angel in a climate protection perspective" (Emissions- und geruchsarme Bauprodukte für energieeffiziente Gebäude - Entwicklung von Anforderungen und Konzepten für den Blauen Engel aus Klimaschutzsicht), founded by the UBA.

The aim of the project is the identification of emissions assessed as odor or as VOC from products to implement these findings into the framework of the Ausschuss zur gesundheitlichen Bewertung von Bauprodukten (AgBB: Committee for the Health Assessment of Construction Products) and the Blue Angel. The results serve to reduce the health impact of emissions from construction products - in this case odor emissions - in the context of consumer protection. With the introduction of the odor assessment in the assessment criteria of the Blue Angel, it is possible to select specifically low-odor and low emitting building materials. The odor investigations are carried out by the
HTW Berlin and the analytical measurements by the BAM, see 2.1 and 2.2 for more details.

\section{Main study}

The evaluation scheme of the AgBB assesses the emissions of volatile organic compounds (VOCs) from building materials. Since VOC emissions are often accompanied by odors that are also annoying, the sensory examination is an important element in the assessment of building materials. Our study is divided into three parts:

1. Odor measurement of products that already have the Blue Angel (construction products and furnishings): a representative number of construction products and furnishings are selected. Among them are carpets, furniture and flooring adhesives. These will be used for the sensory testing (by the HTW) and the AgBB scheme VOC measurement to allow a complete health characterization of the products.

2. Review and further development of existing standards (ISO 1600-28 and VDI 4302-1) of the odor evaluation. E.g. for the perceived intensity and, if necessary, for hedonics, the requirements for the evaluation standard from the previous project are examined and further developed.

3. Odor measurement of different combinations of building materials. Especially in energy-efficient buildings, the energy demand for the ventilation accounts a large part of the total energy demand. It depends proportionally on the fresh air content of the supply air. In order to reduce the energy demand for the ventilation, either the amount of recirculated air is often increased, or the ventilation is reduced as needed. If the outdoor fresh air amount should be reduced it is necessary for a good indoor air quality to use lowemitting and low-odor building products. The energy savings through the use of such building products should be assessed. Therefore, the dilution characteristics of individual building materials as well as a combination of these building materials will be tested.

This paper focuses mainly on the odor assessment of building materials. The results of the chemical assessment are available in the final report of the research project.

\subsection{Sensory measuring sizes}

The sensory evaluation of the perceived air quality is subdivided into various parameters: perceived intensity, hedonic, acceptance and reasonableness [20].

-Perceived Intensity: The perceived odor intensity is the strength of the smell sensation, which is triggered by an odor stimulus. The perceived intensity with the unit pi is an independent sensory quantity, which is determined by trained subjects (8-15 persons) using a reference scale (see 2.3). The subjects compare the intensity of an unknown sample with a known intensity of the reference scale, which uses acetone and air (in increments between 0 and $15 \mathrm{pi}$ ). Zero pi corresponds to an acetone concentration in air of $20 \mathrm{mg} / \mathrm{m}^{3}$. The greater the pi value, the higher the intensity of the corresponding odor. The evaluation of the unknown sample can be done arbitrarily higher (scale is open at the top). ISO 16000-28 (2012) defines $20 \mathrm{mg} / \mathrm{m} 3$ as the odor threshold of acetone [21]. By assessing the perceived intensity 
with a standard for comparison, the subject's subjective sensation is deliberately minimized, thus reducing the standard deviation as well. For the evaluation, the average of the individual answers of a group is formed.

-Hedonic: The hedonic describes whether an olfactory impression is perceived as pleasant or unpleasant. Like the acceptance, this addresses the subjective sensation of the subjects. This value is determined with larger groups of subjects (at least 15 , recommended are 20), so that there is sufficient statistical certainty. The rating is based on the 9-point scale from "extremely unpleasant" $(-4)$ to "extremely pleasant" (+4).

-Acceptance: The assessment of the acceptance is a subjective rating in which subjects determine whether they feel that the air sample is acceptable. They imagine that they are exposed to the odor offered over a longer period continuously. A larger group of subjects (at least 15 , recommended are 25 or more) is needed so that there is sufficient statistical certainty. The evaluation can be done in two ways. The binary yes-no query, which determines a PD value (Percentage Dissatisfied, unit in $\%$ ) or the evaluation on the basis of an acceptance scale. A 20-point scale is used (from -10 "clearly unacceptable" to +10 "clearly acceptable"). The result in both cases is the degree of acceptance.

-Reasonableness: The subjects must decide without a comparative scale, if they feel that the air sample is or is not reasonable for a daily work environment. From this, the reasonableness percentage of an air sample is calculated.

\subsection{Air quality lab and experimental setup}

The structure of the air quality lab for odor evaluation is shown schematically in Figure 2. Figure 3 shows a photo of the air quality laboratory at the HTW Berlin.

The assessments are carried out by the subjects in the test chamber, between measurements the subjects are in a waiting area to recover the sense of smell. The test chamber is built by low-emission materials such as glass and stainless steel. A slight overpressure in the test chamber ensures that the ambient air does not enter the chamber. During the assessment, the emission chambers (B) are lapped by odorless supply air from a distribution box (A).

All material that is in contact with the supply air is made of stainless steel or glass. For the assessment the building materials are placed in the emission test chamber (modified CLIMPAQ) (B) for 28 days each. The term CLIMPAQ is an acronym for "Chamber for Laboratory Investigations of Materials, Pollution and Air Quality" (Figure 4) [22].

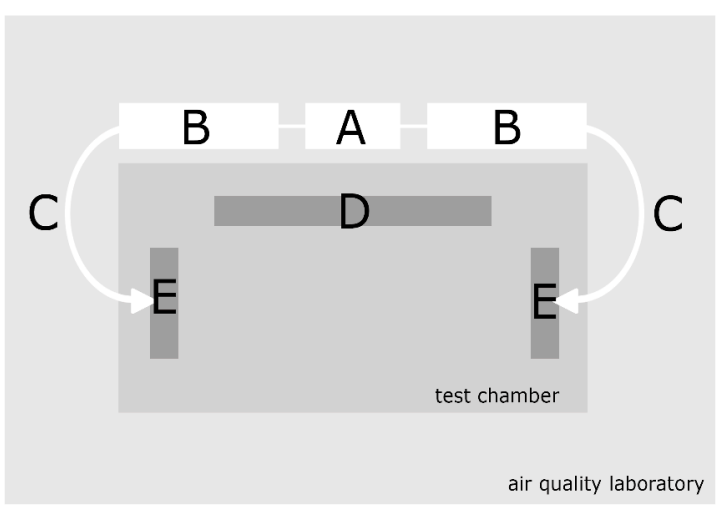

Fig. 2. Schematic layout of the air quality lab at HTW-Berlin

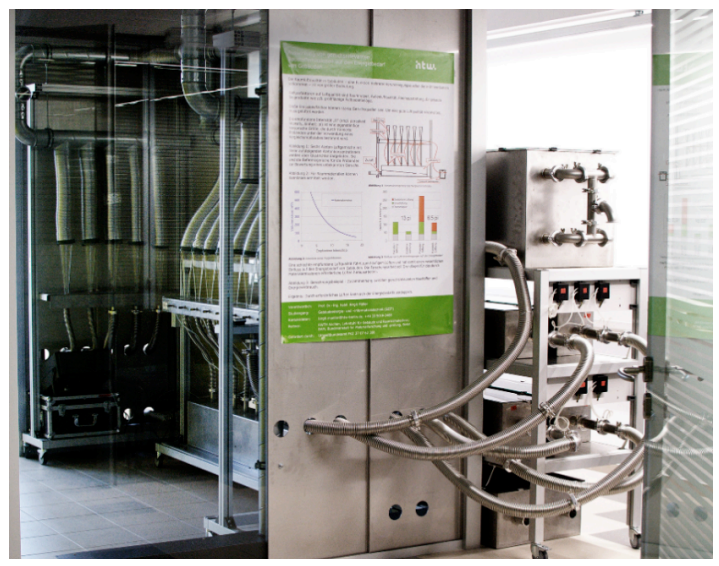

Fig. 3. Air quality laboratory at the HTW Berlin

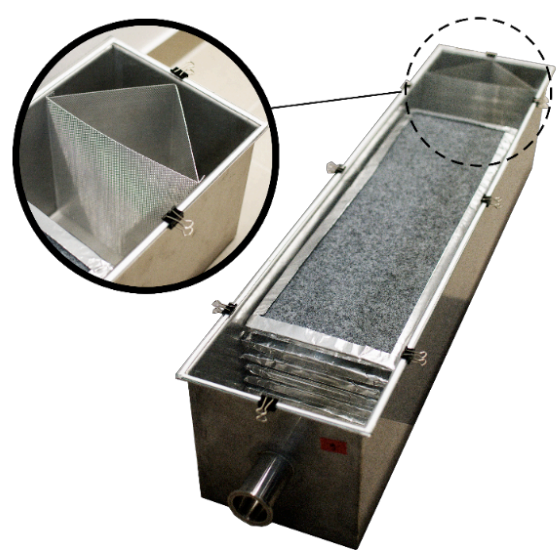

Fig. 4. CLIMPAQ - Emission chamber with carpet samples (B)

$\mathrm{C}$ are the tubes that led the air to the reference scale where the exhaust air is presented to the test subjects with glass funnels (E). For the panel member the emission test chambers with the building material are not visible. The reference scale (D) is used to train/calibrate the subjects, it contains eight funnels with different graduated acetone-air mixtures, see also Figure 5. 


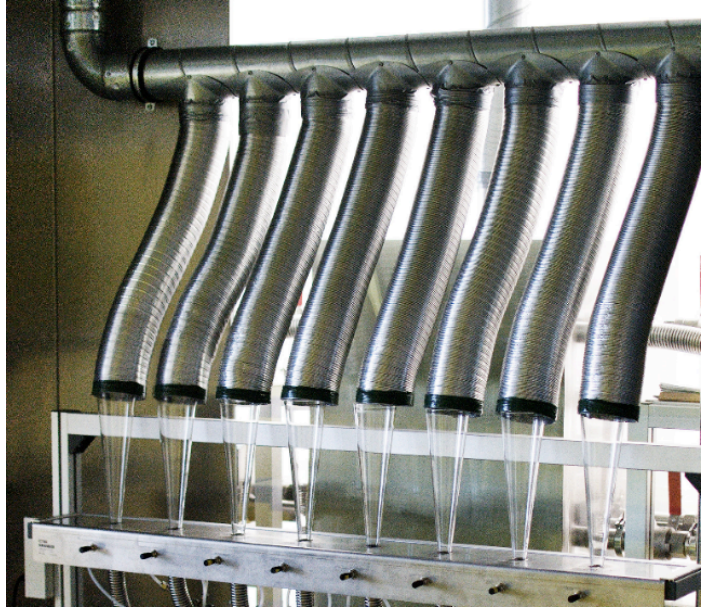

Fig. 5. Reference scale of the HTW-Berlin with individual connecting piece for exhaust air for each funnel.

The air samples are assessed with a relative humidity of $50 \%( \pm 5 \%)$ and the temperature is $23 \pm \mathrm{C}( \pm 2 \pm \mathrm{C})$. It can be assumed that these changes in humidity and temperature have a negligible influence on the results of sensory variables [20].

The reference scale shown in Figure 5 offers 6 different reference stimuli via funnels. As reference substance acetone is used. The reference scale is essentially made up of three parts: sample air flow, acetone source and the metering device. Only low-emission and low-adsorption materials such as stainless steel, glass and Teflon are used for the parts in contact with the air sample in order not to affect the reference stimuli. The reference scale is connected to an odorless air supply. In order to ensure a uniform presentation of the reference substance via the funnels used, the volume flow must be constant between 0.9 and $1.01 / \mathrm{s}$ in each reference funnel [23]. The funnels of the reference scale are designed so that no ambient air enters it due to backflow and mixes with the sample air [20].

\subsection{AgBB-Scheme and Blue Angel}

The AgBB scheme defines the assessment and evaluation concept for emissions of VOCs from construction products [24]. It includes the formulation disclosure and the exclusion of certain hazardous substances and the "requirements for structural health protection". These are used by the Deutsches Institut für Bautechnik as a base for assessing the suitability of construction products in buildings.

The analytical evaluation of the construction products according to the AgBB scheme is carried out by an emission chamber measurement. Corresponding standards [25] [26] [27] [28] form the basis for the measurements. In the AgBB scheme, a sensory test is also included.

The AgBB conducted a pilot phase for sensory testing between 2012 and 2015. The aim of the pilot phase was to examine different building products, test the applicability of the proposed method. The AgBB considers it an unacceptable nuisance when more than $30 \%$ of an untrained, large group of people interviewed rate the odor of building products as unacceptable. Based on such and from health and hygiene perspectives, the $\mathrm{AgBB}$ sets the perceived intensity of $7 \mathrm{pi}$ as a preliminary assessment criterion for the sensory testing of a building product [28]. The determination of VOC and aldehyde emissions, as well as the sensory testing takes place on day 3 and day 28. Figure 6 shows the results from our project and the proposed values for the perceived intensity and the hedonic. Only the perceived intensity is now in the AgBB Schema.

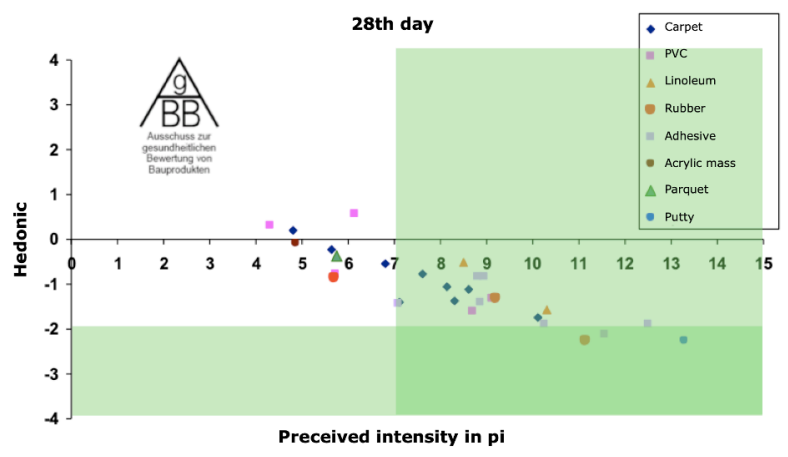

Fig. 6. Results of the floorcoverings and the proposed values for the AgBB-Schema [adapted from 27]

The Blue Angel is a voluntary environmental label that has integrated emission measurements into the Basic Award Criteria for numerous building products and interior fittings. Since the AgBB Scheme raised his value recently to 7 pi for the perceived intensity, it is now equal to the Blue Angel. Since it is a label to distinguish the most ambitious products the value should be adjusted. The discussion is nowadays around 5 pi and for the hedonic to -1 (Figure 7).

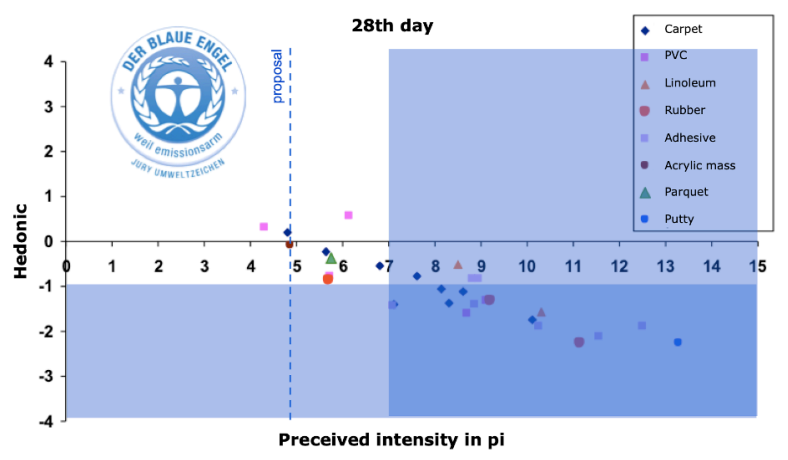

Fig. 7. Results of the floorcoverings and suggested assessment values for the Blue Angel [29]

The Blue Angel environmental label introduced the sensory evaluation for textile floor coverings on the basis of ISO 16000-28. The tested floor coverings may have an odor intensity of not more than 7 pi after 28 days. For a test result of $8 \mathrm{pi}$, another measurement can be performed on the following day. If a value above 7 pi is measured again, the eco-label will be refused. If a maximum value of $7 \mathrm{pi}$ is reached, the product passes the odor test. In any case, follow-up checks must be carried out at least once a year. For products bearing a GUT signet, additional follow-up tests are not required.

\section{Results}

Within the scope of the research project, 22 different textile floor coverings are olfactory assessed. The following figure shows the perceived intensities of these products on day 3 , day 7 , day 14 and day 28 after 
introduction of the products into the emission chambers (CLIMPAQ). Each material sample is shown in a different color.

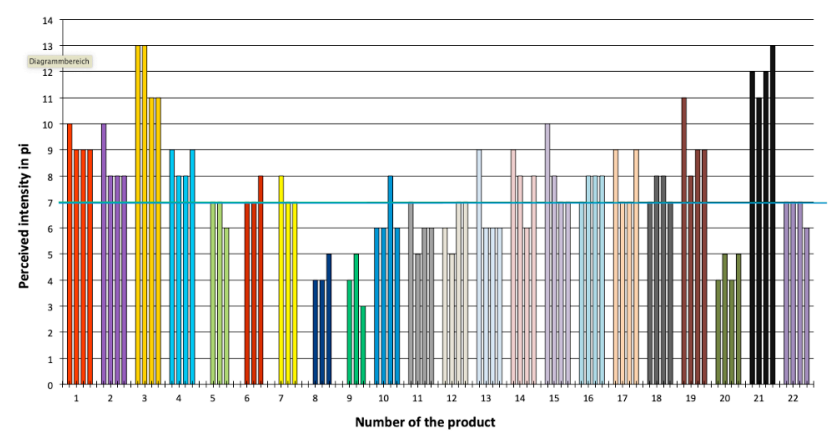

Fig. 8. Results of the perceived intensity of the 22 tested products

Some of the ratings show large differences between them. Thus, products 3 and 21 have very high perceived intensities over 11 pi. Particularly good results are achieved by the products 8,9 and 20 . In total, half of the products tested (50\%) meet the AgBB and Blue Angel criteria (blue and green line, Figure 8).

Figure 9 shows the hedonic ratings of all products. Here, about $41 \%$ of the examined are below the proposed limit value of the Blue Angel (blue line) and about 55\% below the proposed one of the AgBB scheme (green line). Only the product 21 is above both limits.

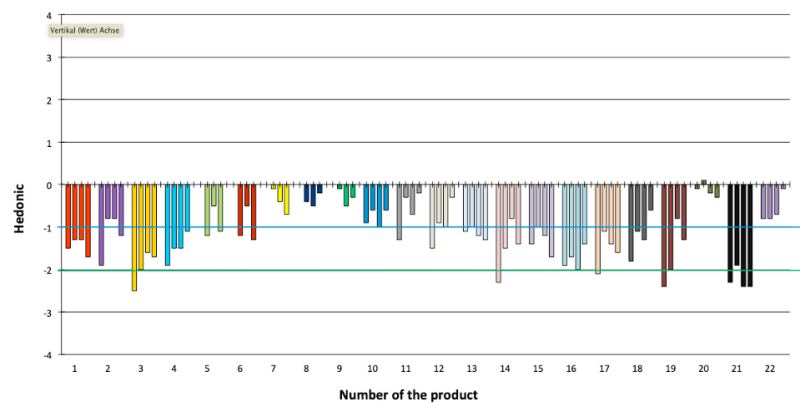

Fig. 9. Results of the hedonics of the 22 tested products

The following figure (Figure 10) shows a comparison of different product groups of floor coverings. The groups differ in the material used for the top layer, polyamide (PA), polypropylene (PP), polyether sulfone (PES) and mixed products.

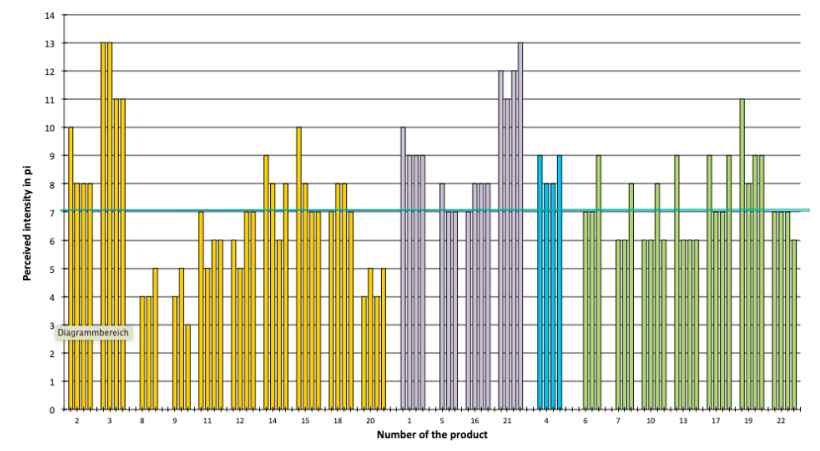

Fig. 10. Comparison of the intensity by top layer
It is noticeable that the products with the very good results (8.9 and 20) have a top layer of $100 \%$ PA (yellow). However, this is also the case for product 3 with the worst value, slightly more than $11 \mathrm{pi}$. The products with a top layer of $100 \%$ PP (purple) all have a reading that exceeds the Blue Angel limit. The products with mixed composition of the top layer partly achieve ratings below the limit value of the $\mathrm{AgBB}$ Scheme and the Blue Angel.

\section{Conclusion}

The AgBB Scheme and the Blue Angel have already been adjusted. Both contain now contains measurement procedures and test criteria for sensory evaluation. The assessed floor coverings may have an odor intensity of not more than 7 pi after 28 days.

\section{References}

1. P. Wargocki, et al., Perceived Air Quality, Sick Building Syndrome Symptoms and Productivity in an Office with two different pollution loads, Denmark: Indoor Air (1999)

2. L. Lagercrantz, et al., Negative impact of air pollution on productivity: previous, Denmark: Department of Tecnology and Resource Management, Mid Sweden University (2000)

3. R. Müller, Atmung, Stoffwechsel und Blutkreislauf, Bd. Praxis der Naturwissenschaften, München: Lehrstuhl für Didaktik der Physik, Universität München (2001)

4. Bundesumweltamt, Das Luftmessnetz des Bundesumweltamtes, Dessau-Roßlau: Umweltbundesamt (2013)

5. R. F. Schmidt, et al., Neuro- und Sinnesphysiologie, Berlin-Heidelberg: Springer Verlag (2006)

6. B. Rasch, Geruchsinduzierte Reaktivierung von Gedächtnisinhalten im menschlichen Schlaf, Trier: Universität Trier (2008)

7. B. Müller, Bewertungsverfahren der Luftqualität in der Gebäudetechnik, Bd. Habilitation, Berlin: Herman Ritschel Institut, Technische Universität Berlin (2008)

8. S. Frings, [Online] Available: http://spektakel.blogsport.de/2011/06/06/zurphysiolgie-des-riechens/ [date: 12 Juli 2016] 2011)

9. P. Plunschke, Luftschadstoffe und Geruchsstoffe in Innenräumen: Herkunft, Verbreitung und Verteilungsmuster in Gebäuden, Nürnberg: Springer-Verlag Berlin Heidelberg (1996)

10. P. Wargocki, Human Perception, Productivity and Symptoms Related to Indoor Air Quality, Bd. Dissertation, Lyngby: Technical University of Denmark (1998) 
11. J. Panaskova, et al., Effects of olfactoryrelavant emissions from building materials in building-energy demands, Austin Texas, USA: Proceedings of Indoor Air 2011 (2011)

12. G. Clausen, et al., Final research manual of "European audit project to optimize indoor air quality and energy consumption in office buildings, Denmark: Technical University of Denmark and TNO-Building and Construction Research (1993.)

13. F. Bittner, et al., Handbuch zur Messung der empfundenen Luftqualität, Berlin: HermanRitschel Institut (2004.)

14. C. Weschler, Chemical reactions among indoor pollutants: what we've learned in the new millennium, Indoor Air (2004)

15. W. Nazaroff et al., Cleaning products and air fresheners: exposure to primary and secondary air pollutants, Atmospheric environment 38 (2004)

16. W. Sakr, et al., The impact of sorption on perceived air quality, Indoor Air (2006)

17. T. Brüning, et al., Gute oder schlechte Luft? Gerüche am Arbeitsplatz und im Innenraum und ihre Bedeutung für die Unfallversicherungsträger, Bochum: IPAJournal (2014)

18. N. v. Hahn et al., Innenraumarbeitsplätze Vorgehensempfehlung für die Ermittlungen zum Arbeitsumfeld, Berlin: DGUV - Druck Center Meckenheim (2013)

19. A. Sensor, Energieeinsparung bei hervorragender Luftqualität, Reutlingen: Applied Sensor (2013)

20. L. Fang, Impact of Temperature and Humidity on Perceived Indoor Air Quality., Kopenhagen: $\mathrm{PhD}$ thesis, Universität von Dänemark (1997)

21. Nordtest method NT Build 482, Building materials: Emissions testing using the CLIMPAQ. ISSN0283-7153, Espoo (1998)

22. Salthammer T., Schulz N., Stolte R., Bartsch J., Uhde E., Human sensory response to acetone/air mixtures, Indoor Air, available online, DOI:10.1111/ina.12262 (2016)

23. F. Bitter, et al., Sensorische Bestimmung der Luftqualität, Berlin: TU- Berlin, HRI

24. UBA, Empfehlungen zur Vorgehensweise bei der gesundheitlichen Bewertung der Emissionen von flüchtigen organischen Verbindungen (VVOC, VOC und SVOC) aus Bauprodukten, Berlin: Bundesumweltamt (2010)

25. DIN ISO 16000-3, Innenraumluftverunreinigungen - Teil 3: Messen von Formaldehyd und anderen, Berlin: BeuthVerlag (2011)

26. DIN ISO 16000-6, Innenraumluftverunreinigungen -Teil 6: Bestimmung von
VOC in der Innenraumluft und in Prüfkammern, Probenahme auf Tenax TA®, thermische Desorption und Gaschromatographie mit MS oder MS-FID, Berlin: Beuth-Verlag (2011)

27. DIN EN ISO 16000-9, Bestimmung der Emission von flüchtigen organischen Verbindungen aus Bauprodukten und Einrichtungsgegenständen - Emissionsprüfkammer-Verfahren, Berlin: Beuth-Verlag (2008)

28. AgBB, Requirements for the Indoor Air Quality in Buildings: Health-related Evaluation Procedure for Emissions of Volatile Organic Compounds (VVOC, VOC and SVOC) from Building Products, Evaluation procedure for VOC emissions from building products, Part 3: LCI values (2018)

29. B. Müller, et al., Sensorische Bewertung der Emissionen aus Bauprodukten - Integration in die Vergabegrundlagen für den Blauen Engel und das AgBB-Schema, Berlin: Bundesumweltamt (2011) 